\title{
Influence of embedded gap and overlap fiber placement defects on the microstructure and shear and compression properties of carbon-epoxy laminates
}

\author{
Lan Marine ${ }^{1,{ }^{*}}$, Cartié Denis ${ }^{2}$, Davies Peter ${ }^{3}$, Baley Christophe ${ }^{1}$
}

${ }^{1}$ University of South Brittany, LIMATB, Rue de Saint Maudé, 56000 Lorient, France

${ }^{2}$ Coriolis Composites SAS, Rue Condorcet, Z.A. du Mourillon, 56350 Quéven, France

${ }^{3}$ Ifremer, Centre Bretagne, Technopôle Brest Iroise, 29280 Plouzané, France

* Corresponding author : Marine Lan, email address : peter.davies@ifremer.fr

\begin{abstract}
:
This paper presents results from an experimental study of the influence of embedded defects created during automated fiber tape placement, on the mechanical properties of carbon/epoxy composites. Two stacking sequences have been examined, $\left[\left(-45^{\circ} / 45^{\circ}\right) 3 /-45^{\circ}\right]$ and $\left[90^{\circ} 4 / 0^{\circ} 3 / 90^{\circ} 4\right]$, in which gaps and overlaps have been introduced during fiber placement. These materials have been cured in an autoclave either with or without a caul plate, then analyzed by ultrasonic C-scan. The microstructures were characterized by scanning electron microscopy. In-plane shear tests were performed on the $\pm 45^{\circ}$ laminates and showed that the use of a caul plate does not affect mechanical behavior of plies in the embedded defect region. Compression tests were performed on $0 / 90^{\circ}$ laminates and in this case the presence of a caul plate is critical during polymerization as it prevents thickness variations and allows defects to heal.
\end{abstract}

Keywords : Structural composites, Defects, Mechanical properties, Mechanical testing 


\section{Introduction}

The automated fiber placement process (AFP) allows the aeronautical industry to produce large primary composite structures with complex shapes. This technology results in high quality manufacturing while reducing production time $[1,2]$.

In order to master the AFP process it is essential to control both the process parameters (heating temperature, compaction pressure, placement speed ...) and the machine trajectories. Various numerical studies have enabled design rules to be developed which optimize these trajectories, so that the final mechanical properties (stiffness and strength) can be maximized $[3,4]$. However, this optimization may cause defects to appear, in the form of gaps or overlaps, which modify local geometry and microstructure. Both numerical and a few experimental studies have focused on the influence of such defects on the final mechanical properties of components [5-12]. Croft et al. [13] have shown that when gaps and overlaps of different dimensions were introduced in the longitudinal direction they did not affect in-plane compression or shear properties. However, when the defects were placed in the transverse direction a drop in shear properties was measured, caused by the fiber waviness resulting from the defects. More recently [14] the influence of gaps and overlaps on tensile properties of carbon/epoxy laminates was studied by the present authors. This study indicated that the presence of a caul plate during autoclave cure can allow healing of defects in some cases. For a laminate with several plies with the same orientation the caul plate completely removed the singularities resulting in only a local thickness variation. The tensile properties were then the same as those in a laminate lay-up without defects. For an alternating stacking sequence the role of the caul plate is less important, but it still encourages material flow and limits local thickness variations.

The aim of the present study is to complete that work [14] on the influence of gaps and overlaps by examining other in-plane loading cases. Embedded gap and overlap defects have 
been introduced into $\left[\left(-45^{\circ} / 45^{\circ}\right)_{3} /-45^{\circ}\right]$ and $\left[90^{\circ}{ }_{4} / 0^{\circ}{ }_{3} / 90^{\circ}{ }_{4}\right]$ laminates. These were then cured either with or without a caul plate in an autoclave in order to study the influence on composite microstructure. Ultrasonic C-scan inspections were performed to check composite quality, then scanning electron microscopy was used to examine the areas where the defects were embedded. Finally, in-plane shear (tension on $\pm 45^{\circ}$ laminates) and compression tests were performed to quantify the effects of embedded defects on mechanical properties.

\section{Material and methods}

\subsection{Material}

The material studied is carbon-reinforced prepreg (8552/AS4/RC34/AW194) from Hexcel Composites [15]. The nominal baseline fiber volume fraction and the nominal cured ply thickness are respectively $57 \pm 2 \%$ and $0.18 \pm 0.01 \mathrm{~mm}$. The prepreg is presented as a tow of width $6.35 \pm 0.25 \mathrm{~mm}$. All plates were manufactured with the same batch of raw material.

\subsection{Choice of lay-up and defect type}

The stacking sequences and defect types were selected to provide information on the influence of extreme cases, compared to the response of the standard aeronautical configuration tested under the same conditions. For shear tests a $\left[\left(-45^{\circ} /+45^{\circ}\right)_{3} /-45^{\circ}\right]$ sequence was selected so that standard in-plane shear tests could be used. Gaps and overlaps were introduced in the third and fourth plies, the two defects were superposed to accentuate their effect. For compression tests an eleven ply $\left[90^{\circ}{ }_{4} / 0^{\circ} 3 / 90^{\circ}{ }_{4}\right]$ sequence was adopted, compatible with the standard test procedure, with defects in all the eight $90^{\circ}$ plies, superposed at the centre of the specimens. These are clearly both severe cases, but were chosen following the experience gained in a previous study on tensile behavior [14] to allow defects to be clearly identified within the composite microstructure and to be able to measure their influence using standard tests. 


\subsection{Manufacture of samples}

To manufacture the different plates, the robot arm and placement head developed by Coriolis Composite were used [16]. This enabled 8 prepreg fiber tows to be laid up simultaneously with a total width of $50.8 \mathrm{~mm}(8 * 6.35 \mathrm{~mm})$ per passage. Heating was by an IR lamp which provides localized heat to enhance adhesion between the succeeding plies. A compaction force of $600 \mathrm{~N}$ was applied during the draping operation. The deposition speed was $0.1 \mathrm{~m} / \mathrm{s}$. To obtain a smooth surface, the first ply was laid up over a film of Teflon Wrightlon 5200 supplied by Airtech ${ }^{\circledR}$ maintained by vacuum. The off-line programming software of the machine was used to create gaps or overlaps in chosen areas of the panels by staggering of sectors.

\subsection{Processing cycle}

The autoclave cycle respected the cure conditions of the pre-impregnated carbon/epoxy provided by the supplier of the material (maximum temperature $180^{\circ} \mathrm{C}$ and maximum pressure 7 bars).

To determine the influence of the presence of a plate during the curing phase in an autoclave, a first series of plates was polymerized without a caul plate. A second set of laminates was polymerized with a caul plate, a $2 \mathrm{~mm}$ thick aluminum plate introduced in the vacuum bag, during the autoclave cure. A Wrightlon 5200 PTFE film provided by AirTech ${ }^{\circledR}$ was placed between the plate and the laminate to allow the flow of the material during the temperature rise and the sliding of the plate during curing.

\subsection{Ultrasonic C-Scan inspections}

For this study, ultrasonic C-Scan was used for analysis of the sample material quality. The ultrasonic C-scan equipment (Sofratest 49944) used for the inspections was equipped with a transducer and a plane aluminum panel acting as a reflector. The control was performed by a 
focused transducer, with a frequency of $10 \mathrm{MHz}$ and a focalization length of $76 \mathrm{~mm}$, which scans in the $\mathrm{X}$ and $\mathrm{Y}$ directions thanks to a motorized system that allows the entire surface of the part to be covered. The acquisition step is $0.5 \mathrm{~mm}$.

\subsection{SEM analysis and Image analysis}

The morphology of the embedded defects and the organization of plies were observed with a Jeol JSM 6460 LV scanning electron microscope. The area examined was located in the middle of the plates, where the defects were introduced during layup. The samples were cut then polished to 1 micron in order to obtain flat, clean surfaces before examination.

Assemblies of several images were necessary to re-create all the zones affected by the defects.

\subsection{Mechanical tests}

Mechanical tests were performed on an Instron ${ }^{\mathrm{TM}}$ hydraulic test machine with a load cell of $50 \mathrm{kN}$ at a loading rate of $2 \mathrm{~mm} / \mathrm{min}$. For each configuration, an average of eight specimens was tested. These specimens were cut from the plates using a diamond tipped disc with water cooling, then the specimen edges were polished to limit crack initiation.

In-plane shear tests were carried out according to the ISO 14129 standard [17] on $\left[\left(-45^{\circ} / 45^{\circ}\right)_{3} /-45^{\circ}\right]$ laminates. In order to limit stress concentrations that may be caused by the clamping system of the tensile testing machine and to avoid premature failure, $2 \mathrm{~mm}$ thick aluminum tabs were bonded to each end of the specimen using a two component epoxy adhesive. Biaxial strain gauges in the axial and transverse directions were placed on one face of the specimen in three locations (one at the middle of the specimen and one at each end). For in-plane shear tests, the Aramis ${ }^{\circledR}(\mathrm{GOM}$, Germany) optical system was used to measure the full-field displacements and strains on the outer plies with Digital Image Correlation. The shear stress was calculated at $5 \%$ shear strain as recommended in the standard, and shear modulus was determined between 0.1 and $0.5 \%$ strain. 
Load-unload cycle tests were also performed on some specimens, by progressively increasing the maximum load until failure. Axial and transverse strain gauges were placed in the center of the specimens in order to measure strains and to calculate modulus and damage factor during load-unload cycles. The initial shear modulus was determined by linear regression over a strain range from 0 to $0.1 \%$. During load-unload cycles the load was increased by $0.8 \mathrm{kN}$ each cycle. The damage factor was calculated using the difference between the initial slopes and those at the maximum stress as defined in the model proposed by Ladevèze [18].

A damage parameter $\mathrm{d}_{(\mathrm{i})}$ was then calculated for each cycle, in order to quantify changes in damage as a function of the associated force $\mathrm{Y}_{\mathrm{d}(\mathrm{i})}$. These two parameters are defined as follows:

$$
\begin{aligned}
& d_{(i)}=1-\frac{G_{12(i)}}{G_{12(0)}} \\
& Y_{d(i)}=\frac{\sigma_{12(i)}{ }^{2}}{2 G_{12(0)}\left(1-d_{(i)}\right)^{2}}
\end{aligned}
$$

Equation 1

Equation 2

where $G_{12(0)}$ is the initial modulus, $G_{12(i)}$ the modulus for cycle (i) and $\sigma_{12(i)}$ is the maximum stress for each cycle $i$.

Compression tests were carried out according to the ISO 14126 standard [19] with the IITRI fixture on the $\left[90^{\circ}{ }_{4} / 0^{\circ} 3 / 90^{\circ}\right.$ ] specimens. In order to limit stress concentrations that may be caused by the clamping system of the tensile testing machine and to avoid premature failure, $0.7 \mathrm{~mm}$ thick glass/epoxy tabs oriented at $\pm 45^{\circ}$ were bonded to each end of the specimen using a two component epoxy adhesive. Longitudinal and transversal strain gauges were bonded in the center on both sides of the specimen. The compression modulus was determined from the slope of the stress-strain curve for a strain range from $0.05 \%$ to $0.25 \%$ following the standard. Compression strength was determined from the force at failure divided by the local cross section at the failure location. 


\section{Results and discussion}

\subsection{In plane shear properties}

\subsubsection{Description of the stacking sequence}

Three series of forty specimens each with seven plies and with a stacking sequence of $\left[\left(-45^{\circ} / 45^{\circ}\right)_{3} /-45^{\circ}\right]$ were manufactured. In these plates, three configurations of embedded defects were introduced during the draping operation. These were designed to represent a critical situation; the defects were introduced in the third ply, oriented at $-45^{\circ}$, and fourth ply, oriented at $+45^{\circ}$, at the point where these cross at the center of each of the plates. The dimensions of the defects, equivalent to half the width of a tow $(3.175 \mathrm{~mm})$, have also been exaggerated to accentuate their effects on shear properties. A plate containing ten specimens of the same configuration without a defect was also manufactured manually under the same conditions of implementation to serve as a reference, Figure 1 (i).

The first configuration contains a $0.5 \mathrm{~mm}$ gap (Figure 1 (ii)). This gap is a machine tolerance required by aircraft manufacturers to avoid extra thickness in manufactured parts [13]. This plate is considered as the aircraft reference when using the automated fiber placement process. The second configuration studied contains a gap of $3.175 \mathrm{~mm}$ (Figure 1 (iii)). This is obtained by offset of the equivalent of a half-tow in the center of the plate in the third and fourth plies. This defect is commonly induced during the production of curved parts when passing from one sector to another. The last configuration studied corresponds to an overlap of $3.175 \mathrm{~mm}$ (Figure 1 (iv)). This is obtained by offsetting by the equivalent of a half-tow at the center of the plate creating a local extra thickness of the third and fourth plies. This defect may be induced in the manufacture of a complex shape which results in a variation of the position of the tapes. The first series of twenty specimens of each defect configuration was manufactured with a caul plate. The second series with exactly the same stacking sequence and defects was then produced without the caul plate. 


\subsubsection{Microstructure analysis}

In order to understand the changes in the mechanical properties and the effects of the embedded defects, it is necessary to look at the laminate microstructure and the morphology of the samples. The C-scan inspection of the plates at $\pm 45^{\circ}$ with gap and overlap defects showed no macro-porosity whatever the type of polymerization used. It was not possible to locate the gaps and overlaps using ultrasonic inspection for any embedded defect configuration studied when the plate was cured with a caul plate. However, when autoclave curing was carried out without a caul plate, the presence of porosity was clearly visible in the samples containing a gap and an overlap of $3.175 \mathrm{~mm}$.

Scanning electron microscopy was performed on polished sections of defects oriented at $45^{\circ}$ in the 3rd or 4th plies, they are thus visible right across the section, as shown in Figure 2. Defects in the $2^{\text {nd }}$ ply are only apparent in the center, at the intersection between the $3 \mathrm{rd}$ and 4 th plies.

These inspections revealed no micro-porosity in the laminate produced by hand lay-up nor in any of the AFP plates. However, the manually laid up plate did reveal a different microstructure with respect to the carbon yarns which were clearly visible in each ply (Figure 3 (i)).

For the AFP laminates with a $0.5 \mathrm{~mm}$ gap there is no sign of the defect (Figure 3 (ii)). There is a variation in microstructure at the carbon yarn level rather than at the tow scale but this has not changed with respect to the reference. The slitting of unidirectional tapes does not degrade the fiber distribution within the cured laminate.

For the laminates containing a $3.175 \mathrm{~mm}$ wide gap cured without a caul plate (Figure 3 (iii)), the missing material in the third ply can be clearly noted. The $+45^{\circ}$ tows in the fourth ply are not visible at the ply intersection in the center of the specimen. For curing with a caul plate a 
region with lower fiber content is noted in the third ply. This region was filled by epoxy resin but there is still evidence of the embedded defect. In the adjacent plies the fiber content is increased, but the caul plate has limited the thickness variation.

For the laminate with an overlap, Figure 3 (iv), there is an increase in thickness when no caul plate is used. The quantity of fibers in the fourth ply (observed in the direction at $45^{\circ}$ to the embedded defect) increases when there is no caul plate. A larger thickness is also observed in the $3^{\text {rd }}$ ply in the center. Once again the use of a caul plate reduces the thickness variation (Figure 4), but the alternating stacking sequence restrains movement of the fibres during cure and the defect is not completely healed.

\subsubsection{Results of In-plane shear tests}

Following this microstructural analysis, in-plane shear tests were performed. All the specimens failed at $45^{\circ}$ with extensive delamination. For the reference samples with a $0.5 \mathrm{~mm}$ gap failures were randomly distributed along the specimens. For $3.75 \mathrm{~mm}$ gaps and overlaps, failure always occurred at the center of the specimen near the embedded defect, whether or not a caul plate was used during cure. The shear stress-shear strain plots for these tests showed the same non-linear behaviour in all cases (Figure 5). An initial linear behaviour was visible before micro-cracking; this was used to compute the apparent shear modulus. Then a flatter slope with a drop in stiffness is observed with a re-orientation of the plies in the loading direction.

Figure 6 and Table 1 show the shear modulus values, measured at the specimen center in the embedded defect region. The local increase in thickness of the specimens with an overlap of half a tape results in a slight increase in modulus, of between $1.8 \%$ and $2 \%$, compared to the 
AFP reference specimens. The presence of a gap leads to a drop of 5 to $10 \%$, with or without caul plate, compared to the manual or AFP $0.5 \mathrm{~mm}$ gap reference values.

The shear stresses at 5\% shear strain are shown in Figure 7 and Table 1. These were measured in the embedded defect region. For the laminates with a gap of $0.5 \mathrm{~mm}$ the stresses are similar, with mean values of 110 and $115 \mathrm{MPa}$ with or without caul plate. These values are slightly lower than the manual reference. For a larger gap a drop in shear stress is noted and the shear stress is lower by about $15 \%$ when no caul plate is used, compared to the AFP reference. This is caused by the local thickness variation and the local changes in fiber content in adjacent plies noted earlier. The introduction of an overlap does not affect the shear stress values at $5 \%$ strain. The caul plate reduces the thickness variation in this case and shear stress at $5 \%$ strain increases slightly (by about 5\% compared to the AFP reference). With respect to the shear stress values at final failure the gap tends to reduce the mean values slightly, with or without caul plate from 110 to $115 \mathrm{MPa}$ for the AFP reference to between 100 and $110 \mathrm{MPa}$. Failure stresses of specimens with overlaps and produced without a caul plate are unchanged, but when a caul plate is used this value drops to around $100 \mathrm{MPa}$.

\subsection{Load/Unload shear cycles}

The tension tests on specimens laid up at $\pm 45^{\circ}$ provide the shear properties of the different AFP laminates. In order to examine whether the embedded defects affect the damage development a series of specimens was tested with load/unload cycles. This allows the onset and progression of damage to be examined by measuring changes in stiffness [17]. The specimens have the same stacking sequence $\left[\left(-45^{\circ} /+45^{\circ}\right){ }_{3} /-45^{\circ}\right]$, as those described previously and the same embedded defects (Figure 1). Figure 8 shows examples of stress-strain curves for the different specimens. 
Figure 9 shows how the modulus changes during cycling. The damage factor $\mathrm{d}$ varies and is plotted versus the associated force $\left(\mathrm{Y}_{\mathrm{d}}\right)$ in Figure 10. For all defects a damage threshold is noted after three load/unload cycles, at a shear strain of around $0.15 \%$, then the modulus starts to drop and the damage factor increases. These results suggest that the damage development is not significantly affected by the embedded defects.

\subsection{Compression properties}

\subsubsection{Description of stacking sequence}

In the second part of this study the influence of the embedded defects on compression behavior was studied. Two series of four plates, each with eleven plies $\left[90^{\circ}{ }_{4} / 0^{\circ}{ }_{3} / 90^{\circ}{ }_{4}\right]$, were manufactured by AFP. The embedded defects have again been designed to represent the most critical situations. Indeed, they were introduced into all the plies oriented at $90^{\circ}$ and superimposed on each other at the center of each of the plates. The dimensions of the defects have also been exaggerated to accentuate their effects on mechanical properties, with the same configurations as the previous study: $0.5 \mathrm{~mm}$ gap as reference (Figure 11 (ii)), then $3.175 \mathrm{~mm}$ gap (Figure 11 (iii)) and $3.175 \mathrm{~mm}$ overlap (Figure 11 (iv)). A reference plate was produced manually, without defects (Figure 11 (i)), with the same sequence and at the same time, for comparison. The first series of four plates was manufactured with a caul plate. A second series of four plates with exactly the same stacking sequence and defects was then produced without the caul plate.

\subsubsection{Microstructure analysis}

C-scan inspection of all plates indicated no significant defects outside the embedment regions. Only a variation in thickness revealed the presence of defects in samples cured without a caul plate for the gap and overlap of half-tow width $(3.175 \mathrm{~mm})$. 
Scanning electron microscopy revealed no porosity in any of the plates. For the reference samples with a gap of $0.5 \mathrm{~mm}$ (Figure 12 (ii)) there is no sign of the gap with or without caul plate. For the laminates with a $3.175 \mathrm{~mm}$ gap manufactured without a caul plate, two resin rich zones are visible in the $90^{\circ}$ plies (Figure 12 (iii)). The defect in the four lower plies has been partly filled during cure but those in the four upper plies in contact with the vacuum bag have not been filled. In the latter the autoclave pressure has pushed the material away from the defect. A significant swelling of the central plies at $90^{\circ}$ has also introduced a large thickness variation. When specimens with the same defect were cured with a caul plate however, the defects were completely healed both on the mould side and the side in contact with the caul plate, due to the pressure distribution during cure (Figure 12 (iii)). Only a slight thickness variation remains.

For the specimens with the overlap defect a local variation in thickness of all the plies is apparent. The presence of the embedded defect will alter the stress state, but the tests were analyzed as if the specimens were homogeneous The thickness variation is limited when a caul plate is employed. Without the caul plate a large increase in thickness is noted (Figure 13).

\subsubsection{Results of compression tests}

Compression tests were then performed on all specimens. The stress-strain curves recorded, Figure 14, show the strain behavior measured on both surfaces of specimens with the AFP reference gap, a gap of $3.175 \mathrm{~mm}$ and an overlap of $3.175 \mathrm{~mm}$. These plots show that the introduction of severe defects leads to buckling before failure. This occurs on the surface of the specimens either in contact with the caul plate or the vacuum bag.

Figure 15 and Table 1 show the variation of the compression modulus measured on the surface of the specimens in contact with the mold during cure. The theoretical tensile modulus 
for this stacking sequence is $45.7 \mathrm{GPa}$. The values for the manually laid-up, AFP reference material and with a $3.175 \mathrm{~mm}$ are all very similar with and without caul plate. For the overlap cured with a caul plate however, there is an increase in apparent modulus due to the buckling of the specimens. When no caul plate is used the apparent modulus drops, due to the variation in cross-section and the increased resin content in the $0^{\circ}$ plies near the defects.

The apparent compression strengths, calculated in the defect zones, are shown in Figure 16 and Table 1. The $0.5 \mathrm{~mm}$ gap has no effect compared to the values for the manually laid-up specimens. The $3.175 \mathrm{~mm}$ gap produced with a caul plate results in a drop of $12 \%$ compared to the AFP reference due to the small thickness variation, and $20 \%$ without a caul plate due to the larger thickness variation. The overlap results in a similar drop to the gap when a caul plate is used. Without the caul plate the thickness change causes a large drop in strength of around 55\% compared to the reference AFP specimens. These results correspond to an extreme case in which several superposed defects are tested. It should be emphasized that staggering of these defects will limit their influence significantly, as has been shown previously, e.g. [20].

\section{Conclusion}

The results from this experimental study show the influence of severe embedded defects on the microstructure and in-plane shear and compression properties of carbon-epoxy laminates. Two stacking sequences, containing gaps and overlaps were analyzed. First, an alternating lay-up $\left[\left(-45^{\circ} / 45^{\circ}\right)_{3} /-45^{\circ}\right]$ was studied. The presence of gap and overlap defects in two different plies prevented healing of the microstructure resulting in resin-rich regions for gaps and fiber-rich regions for overlaps. These effects were limited by curing with a caul plate. Inplane shear test results indicated that overlaps were less critical than gaps for shear properties, 
particularly when the caul plate was used. Load/unload cycles showed similar damage development for all specimens.

Then a $\left[90^{\circ}{ }_{4} / 0^{\circ} 3 / 90^{\circ}{ }_{4}\right]$ stacking sequence was examined. The superposition of plies with the same orientation allows partial healing of gaps and overlaps during cure without a caul plate and complete healing when a caul plate was used. Compression tests were dominated by buckling, resulting in a strong influence of defects when no caul plate was used. The use of a caul plate limits this failure mechanism.

\section{Acknowledgements}

The authors would like to thank the region of Brittany (France) and the Regional Council of Morbihan for their financial support. The authors also gratefully acknowledge Amaury

Ducloux and Gildas Leverger (Coriolis Composite) for the manufacture of plates by Automated Fiber Placement, and Luc Riou (Ifremer) for the ultrasonic C-Scan analysis.

\section{References}

[1] Goldworthy W. Geodesic path length compensator for composite-tape placement head. Patent US 3810.805; 14th May 1974.

[2] Lukaszewicz DH-JA, Ward C, Potter KD. The engineering aspects of automated prepreg layup: History, present and future. Composites Part B: Engineering 2012;43:997-1009. doi:10.1016/j.compositesb.2011.12.003.

[3] Lopes CS, Gürdal Z, Camanho PP. Variable-stiffness composite panels: Buckling and first-ply failure improvements over straight-fibre laminates. Computers \& Structures 2008;86:897-907. doi:10.1016/j.compstruc.2007.04.016.

[4] Arian Nik M, Fayazbakhsh K, Pasini D, Lessard L. A comparative study of metamodeling methods for the design optimization of variable stiffness composites. Composite Structures 2014;107:494-501. doi:10.1016/j.compstruct.2013.08.023.

[5] Sawicki A, Minguett P. The effect of intraply overlaps and gaps upon the compression strength of composite laminates. 39th AIAA/ASME/ASCE/AHS/ASC Structures, Structural Dynamics, and Materials Conference and Exhibit, American Institute of Aeronautics and Astronautics; 1998. 
[6] Turoski LE. Effects of manufacturing defects on the strength of toughened carbon/epoxy prepreg composites. Master of Science, Montana State University, Mechanical Engineering, Bozeman; 2000.

[7] Blom AW, Lopes CS, Kromwijk PJ, Gurdal Z, Camanho PP. A Theoretical Model to Study the Influence of Tow-drop Areas on the Stiffness and Strength of Variablestiffness Laminates. Journal of Composite Materials 2009;43:403-25. doi: $10.1177 / 0021998308097675$.

[8] Legay P. Étude de l'influence de défauts sur les propriétés mécaniques de matériaux composites fabriqués par le procédé de placement de fibres. $\mathrm{PhD}$ Thesis. École Polytechnique de Montréal, 2011.

[9] Fayazbakhsh K, Arian Nik M, Pasini D, Lessard L. Defect layer method to capture effect of gaps and overlaps in variable stiffness laminates made by Automated Fiber Placement. Composite Structures 2013;97:245-51. doi:10.1016/j.compstruct.2012.10.031.

[10] Arian Nik M, Fayazbakhsh K, Pasini D, Lessard L. Optimization of variable stiffness composites with embedded defects induced by Automated Fiber Placement. Composite Structures 2014;107:160-6. doi:10.1016/j.compstruct.2013.07.059.

[11] Falcó O, Lopes CS, Mayugo JA, Gascons N, Renart J. Effect of tow-drop gaps on the damage resistance and tolerance of Variable-Stiffness Panels. Composite Structures 2014;116:94-103. doi:10.1016/j.compstruct.2014.05.005.

[12] Li X, Hallett SR, Wisnom MR. Modelling the effect of gaps and overlaps in automated fibre placement (AFP)-manufactured laminates. Science and Engineering of Composite Materials 2015;22:115-29.

[13] Croft K, Lessard L, Pasini D, Hojjati M, Chen J, Yousefpour A. Experimental study of the effect of automated fiber placement induced defects on performance of composite laminates. Composites Part A: Applied Science and Manufacturing 2011;42:484-91. doi:10.1016/j.compositesa.2011.01.007.

[14] Lan M, Cartié D, Davies P, Baley C. Microstructure and tensile properties of carbonepoxy laminates produced by automated fibre placement: Influence of a caul plate on the effects of gap and overlap embedded defects. Composites Part A: Applied Science and Manufacturing 2015;78:124-34. doi:10.1016/j.compositesa.2015.07.023.

\section{[15] http://www.hexcel.com/fr/ 2015.}

[16] http://www.coriolis-composites.com/ 2015. 
[17] NF EN ISO 14129 - Composites plastiques renforcés de fibres - Détermination de la réponse contrainte-déformation en cisaillement plan, module et résistance compris, par essai de traction à plus ou moins 45 degrés; April 1998

[18] Ladeveze P, LeDantec E. Damage modelling of the elementary ply for laminated composites. Composites Science and Technology 1992;43:257-67. doi:10.1016/02663538(92)90097-M.

[19] NF EN ISO 14126 - Composites plastiques renforcés de fibres - Détermination des caractéristiques en compression dans le plan; January 2000

[20] Falcó O, Mayugo JA, Lopes CS, Gascons N, Costa J. Variable-stiffness composite panels: defect tolerance under in-plane tensile loading. Compos Part A Appl Sci Manuf 2014;63:21-31. 


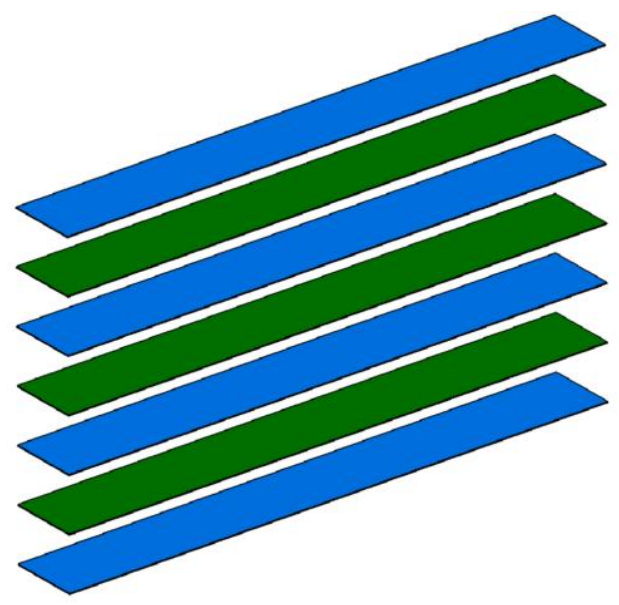

(i) Manual layup - Without defects

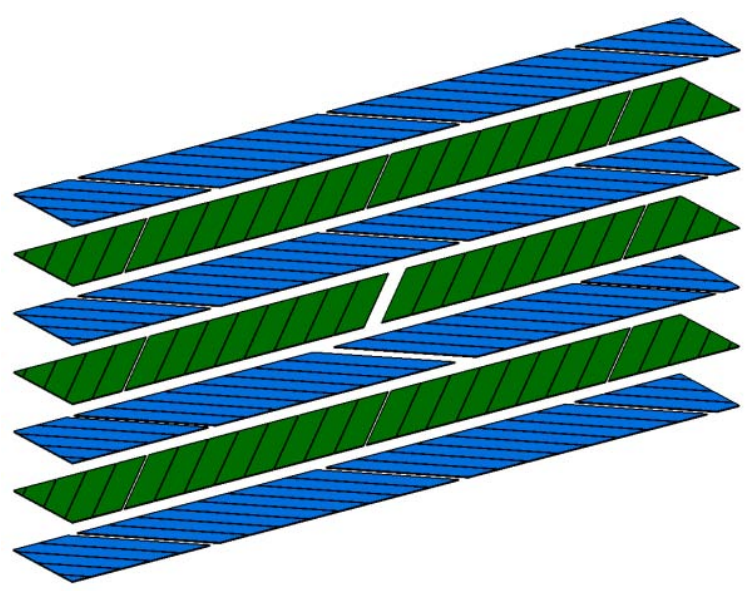

(iii) AFP layup - Gap $3.175 \mathrm{~mm}$

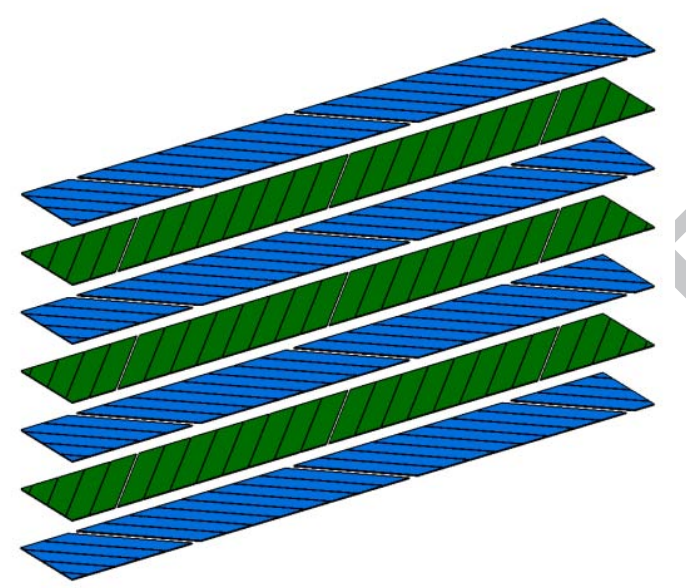

(ii) AFP layup - Gap $0.5 \mathrm{~mm}$

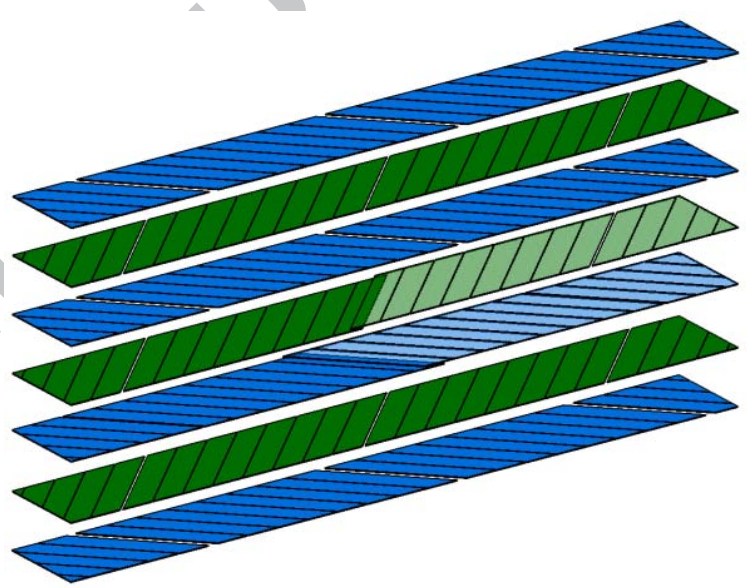

(iv) AFP layup - Overlap $3.175 \mathrm{~mm}$

Figure 1 - Specimen layups, $\left[\left(-45^{\circ} / 45^{\circ}\right)_{3} /-45^{\circ}\right]$ showing embedded defects. Plies oriented at $-45^{\circ}$ are shown in blue and plies oriented at $+45^{\circ}$ are shown in green. (For interpretation of the references to colour in this figure legend, the reader is referred to the web version of this article.)
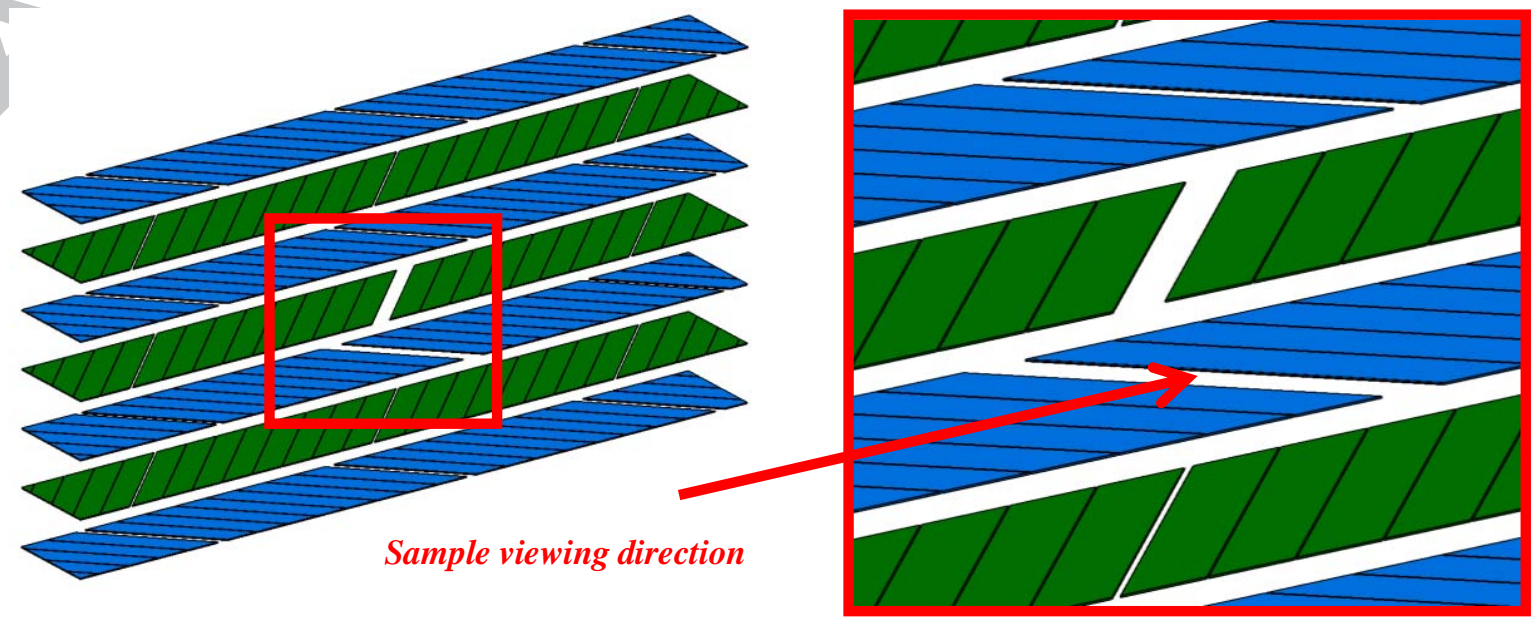
Figure 2 - Specimen geometry for microstructure observation

(i) Manual layup - Without embedded defect - With caul plate

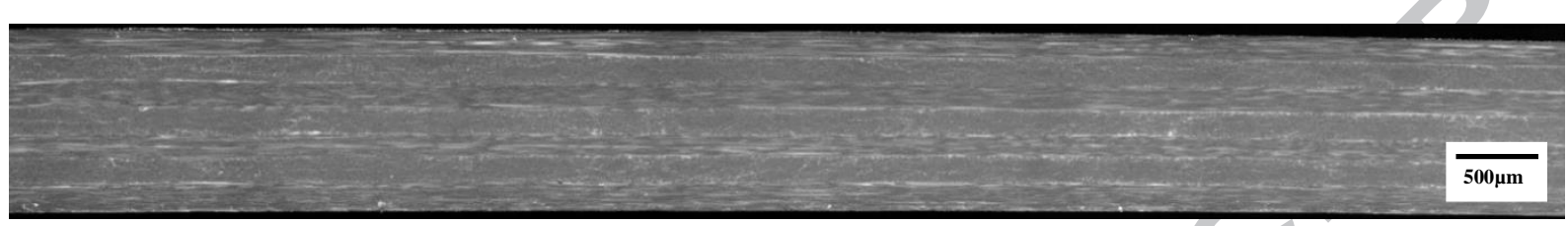

(ii) AFP layup - Gap $0.5 \mathrm{~mm}$ - Without caul plate

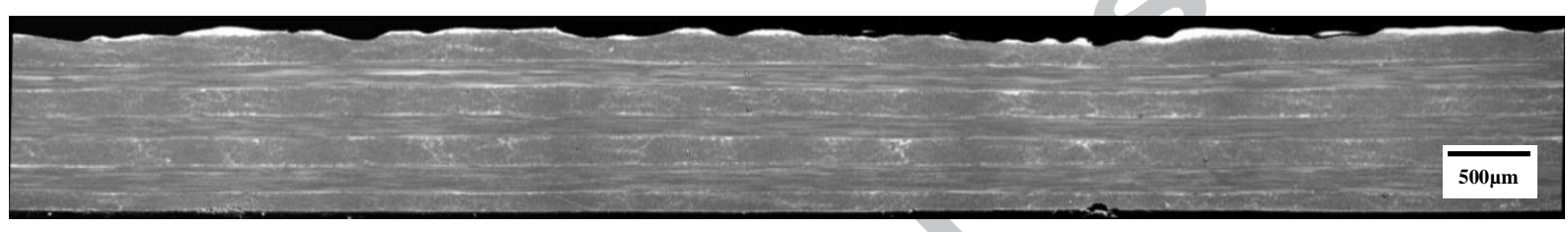

(ii) AFP layup - Gap $0.5 \mathrm{~mm}$ - With caul plate

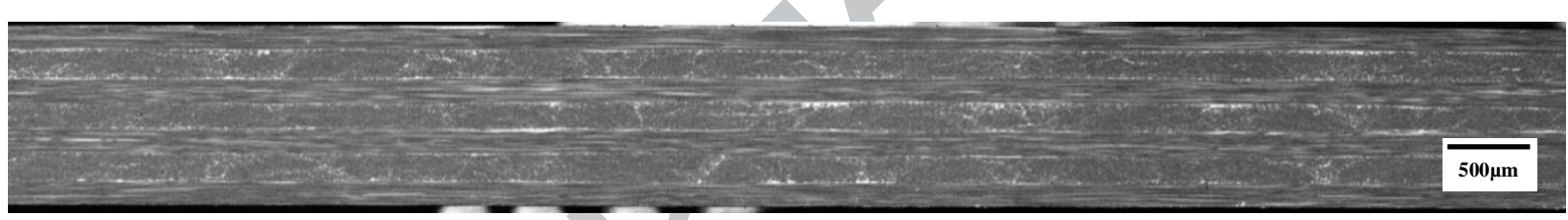

(iii) AFP layup - Gap 3.175 mm - Without caul plate

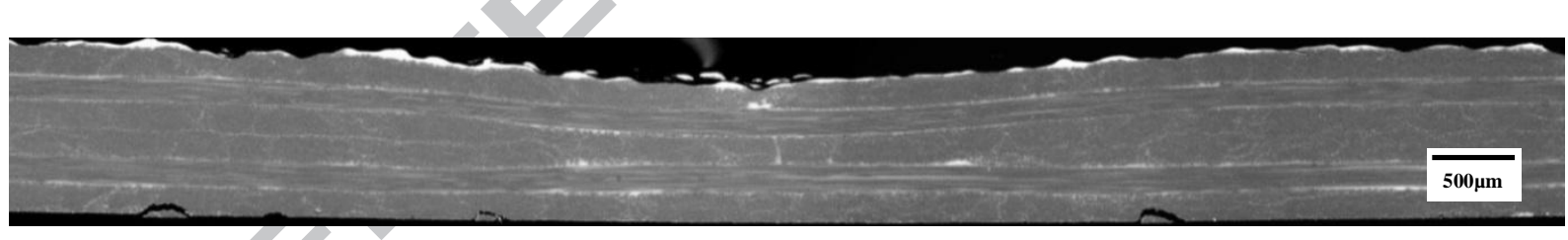

(iii) AFP layup - Gap $3.175 \mathrm{~mm}$ - With caul plate

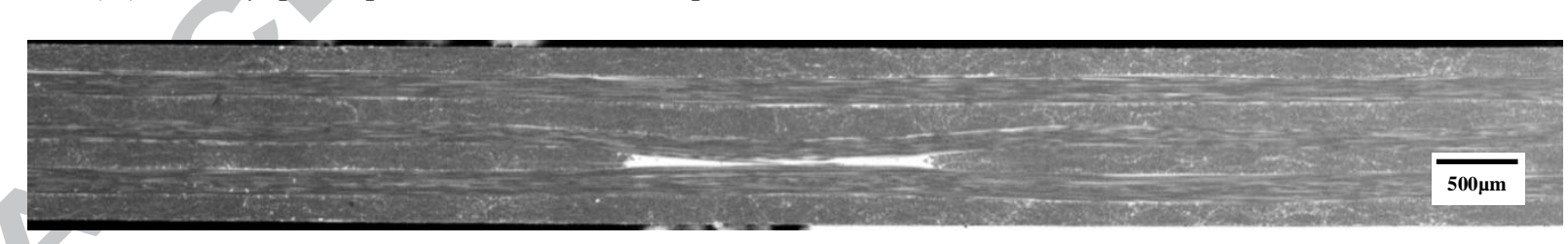

(iv) AFP layup - Overlap $3.175 \mathrm{~mm}$ - Without caul plate

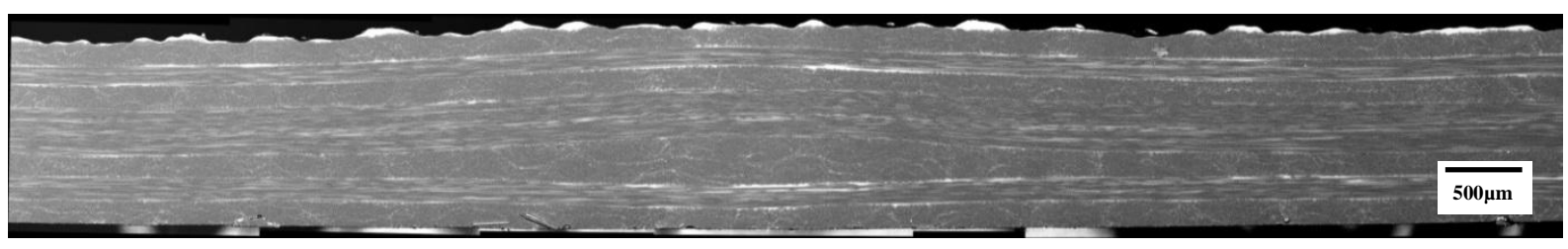

(iv) AFP layup - Overlap $3.175 \mathrm{~mm}$ - With caul plate 


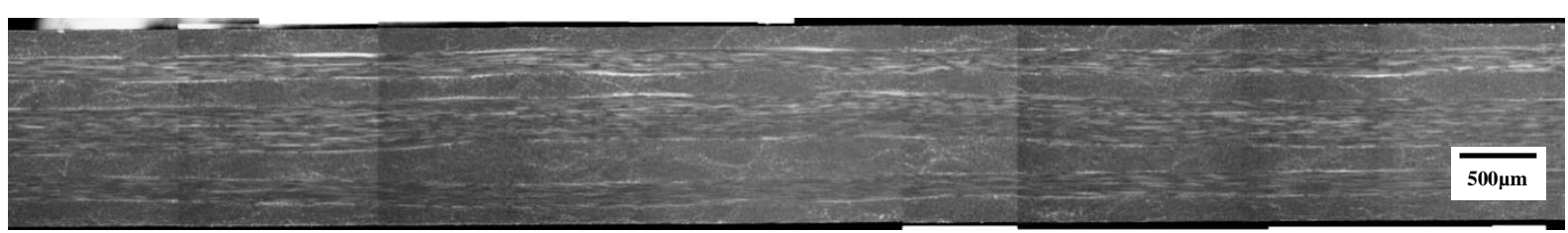

Figure 3 - Microstructural SEM observations in the embedded defect region, $\left[\left(-45^{\circ} /+45^{\circ}\right)_{3} /-45^{\circ}\right]$ : (i) Manual layup; (ii) Reference AFP layup; (iii) AFP plate with a gap of $3.175 \mathrm{~mm}$; (iv) AFP plate with an overlap of 3.175 $\mathrm{mm}$

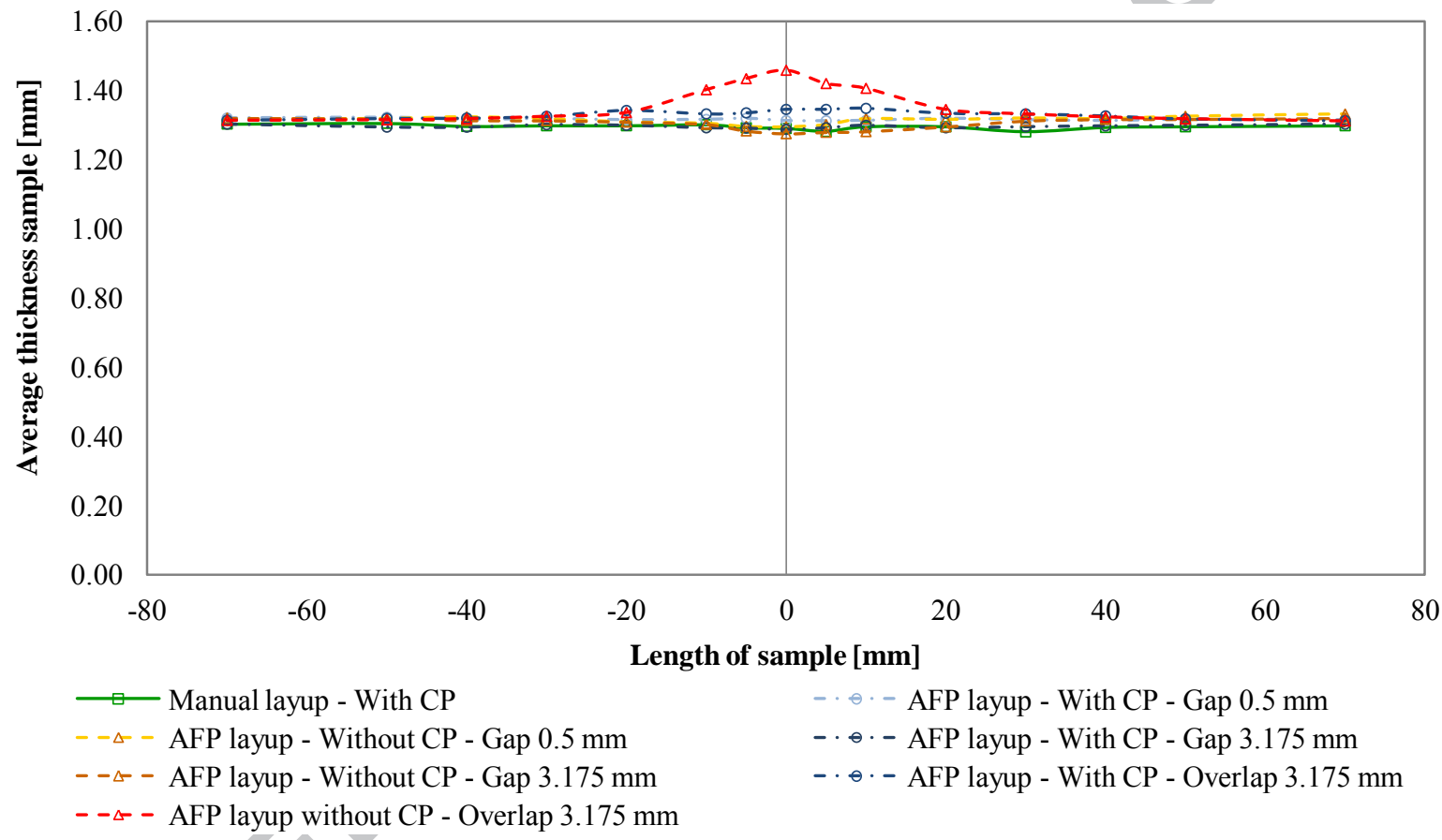

Figure 4 - Variations in the thickness along the length of samples according to the embedded defects introduced during the draping phase, $\left[\left(-45^{\circ} / 45^{\circ}\right)_{3} /-45^{\circ}\right]$. (For interpretation of the references to colour in this figure legend, the reader is referred to the web version of this article.) 


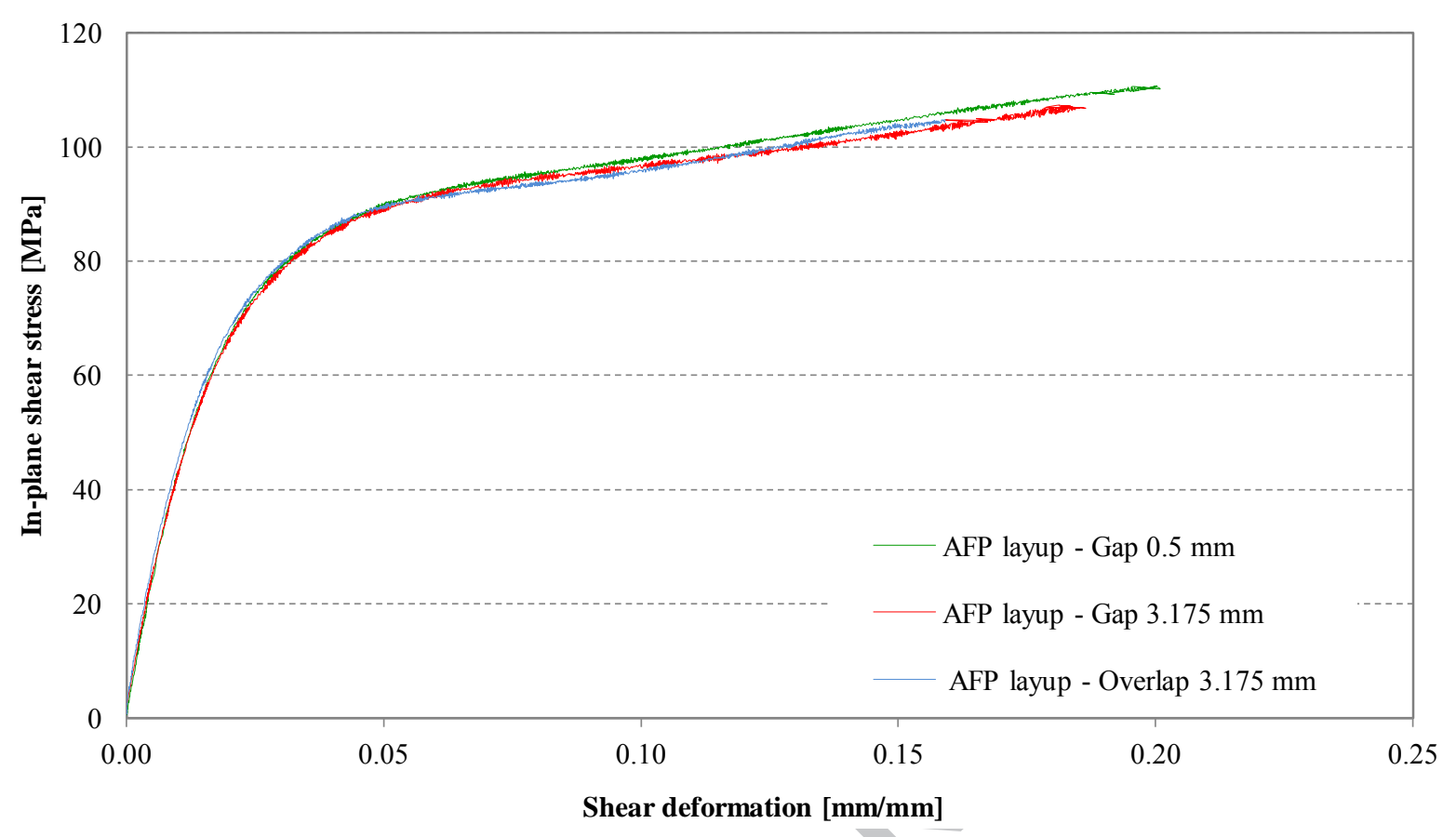

(i) 
(ii)

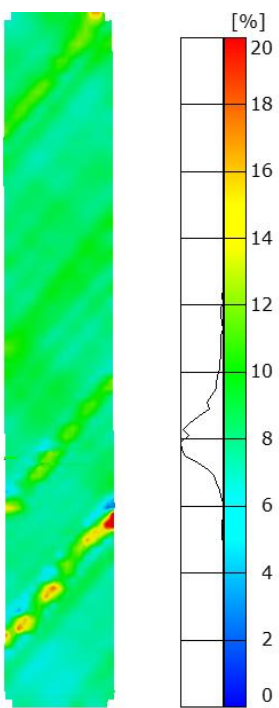

AFP layup - Gap $0.5 \mathrm{~mm}$
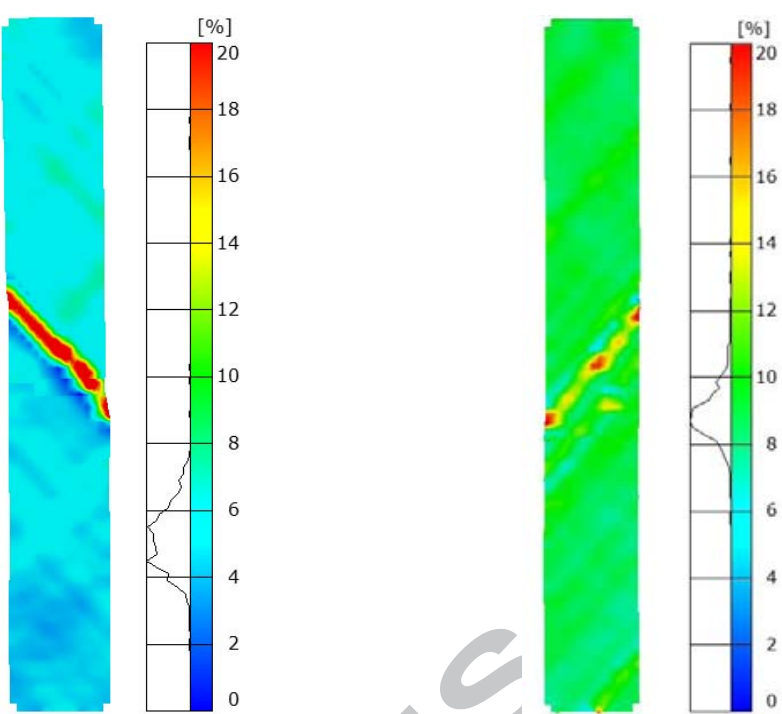

AFP layup - Gap 3.175 mm
AFP layup - Overlap $3.175 \mathrm{~mm}$

Figure 5 - (i) In plane shear stress - strain curve as a function of the type of embedded defect, (ii) Major strain before failure as a function of the type of defect measured by image correlation from the in-plane shear tests. (For interpretation of the references to colour in this figure legend, the reader is referred to the web version of this article.)

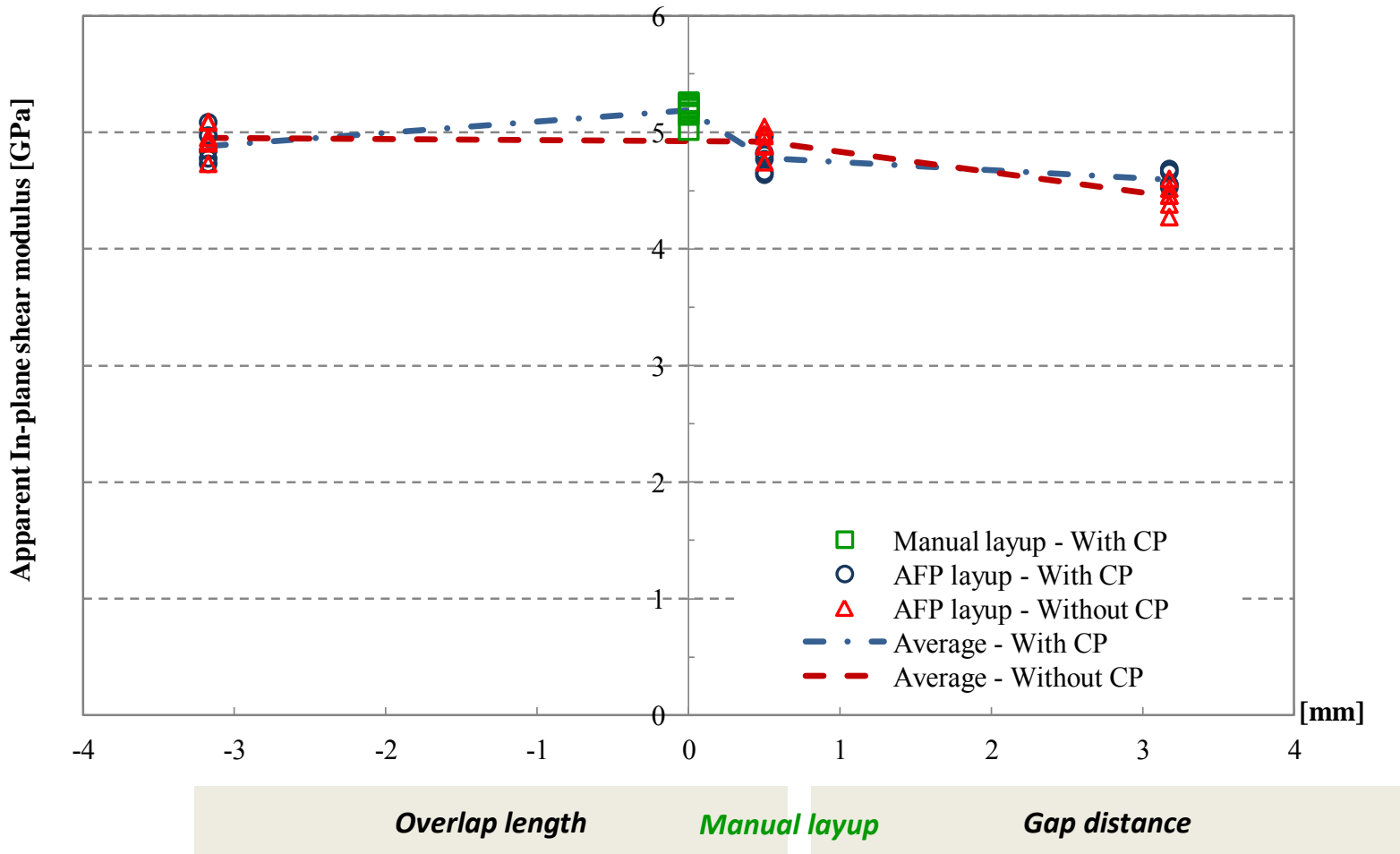


Figure 6-Apparent in-plane Shear modulus variation as a function of the type of embedded defect with and without caul plate, $\left[\left(-45^{\circ} / 45^{\circ}\right)_{3} /-45^{\circ}\right]$. (For interpretation of the references to colour in this figure legend, the reader is referred to the web version of this article.)

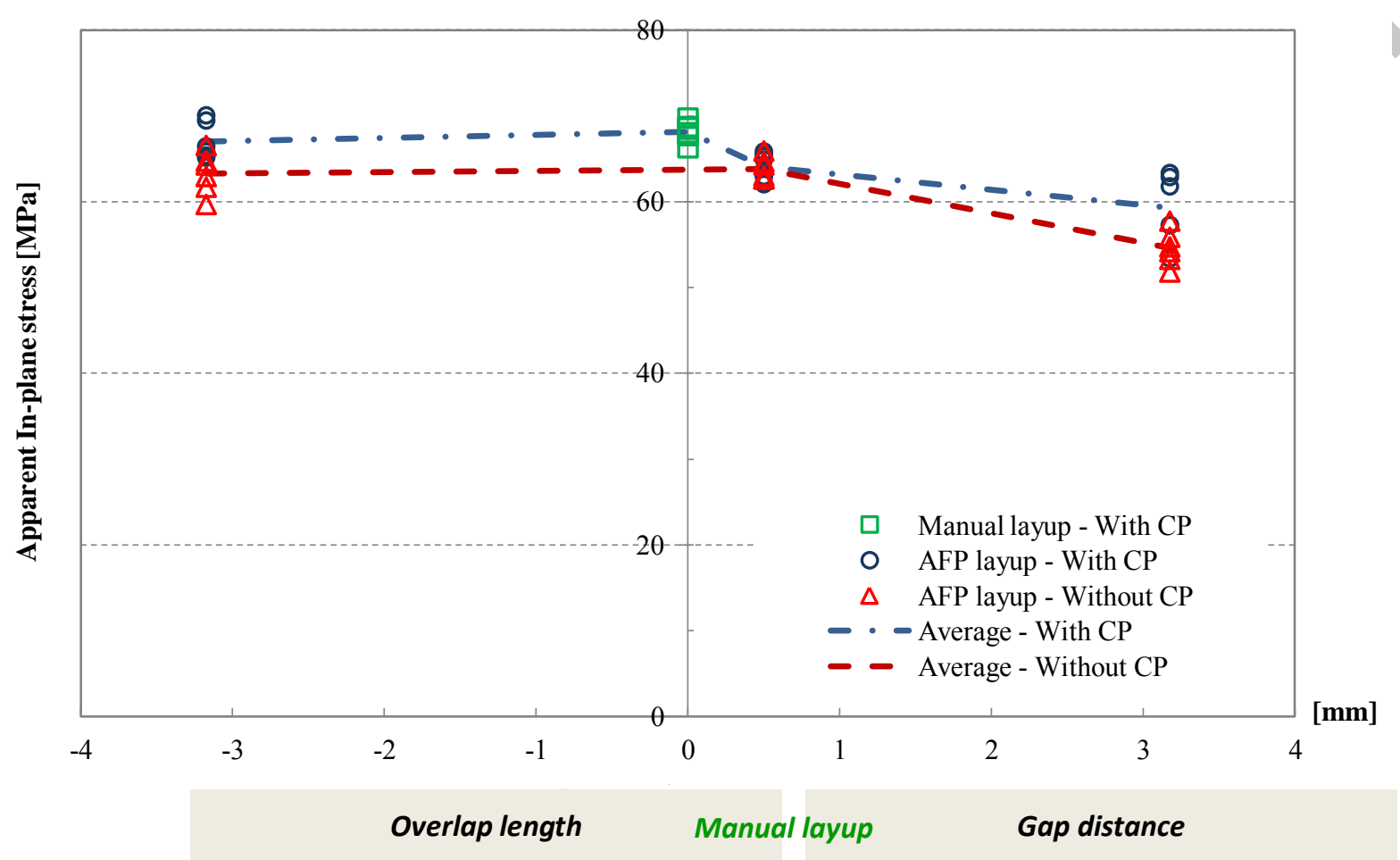

Figure 7 - Apparent in plane stress variation as a function of the type of embedded defect with and without caul plate, for $5 \%$ strain,

$\left[\left(-45^{\circ} /+45^{\circ}\right)_{3} /-45^{\circ}\right]$. (For interpretation of the references to color in this figure legend, the reader is referred to the web version of this article.) 


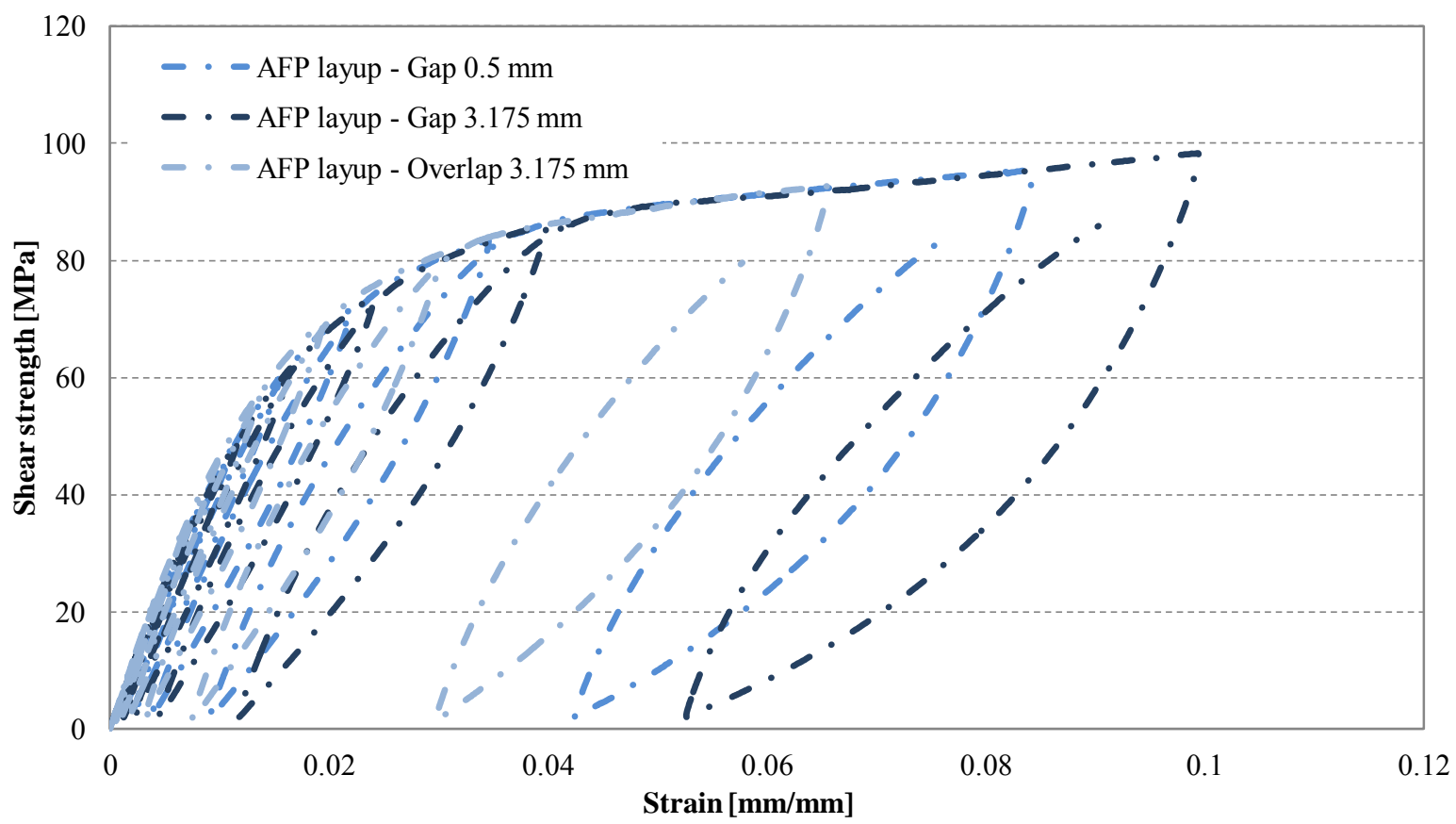

Figure 8 - Load/unload cycles. Shear stress - shear strain curves for different embedded defects. (For interpretation of the references to colour in this figure legend, the reader is referred to the web version of this article.)



Figure 9 - Apparent In-Plane shear modulus variation as a function of the type of embedded defect, polymerized with and without caul plate, and cycle number, $\left[\left(-45^{\circ} / 45^{\circ}\right)_{3} /-45^{\circ}\right]$. (For interpretation of the references to color in this figure legend, the reader is referred to the web version of this article.) 


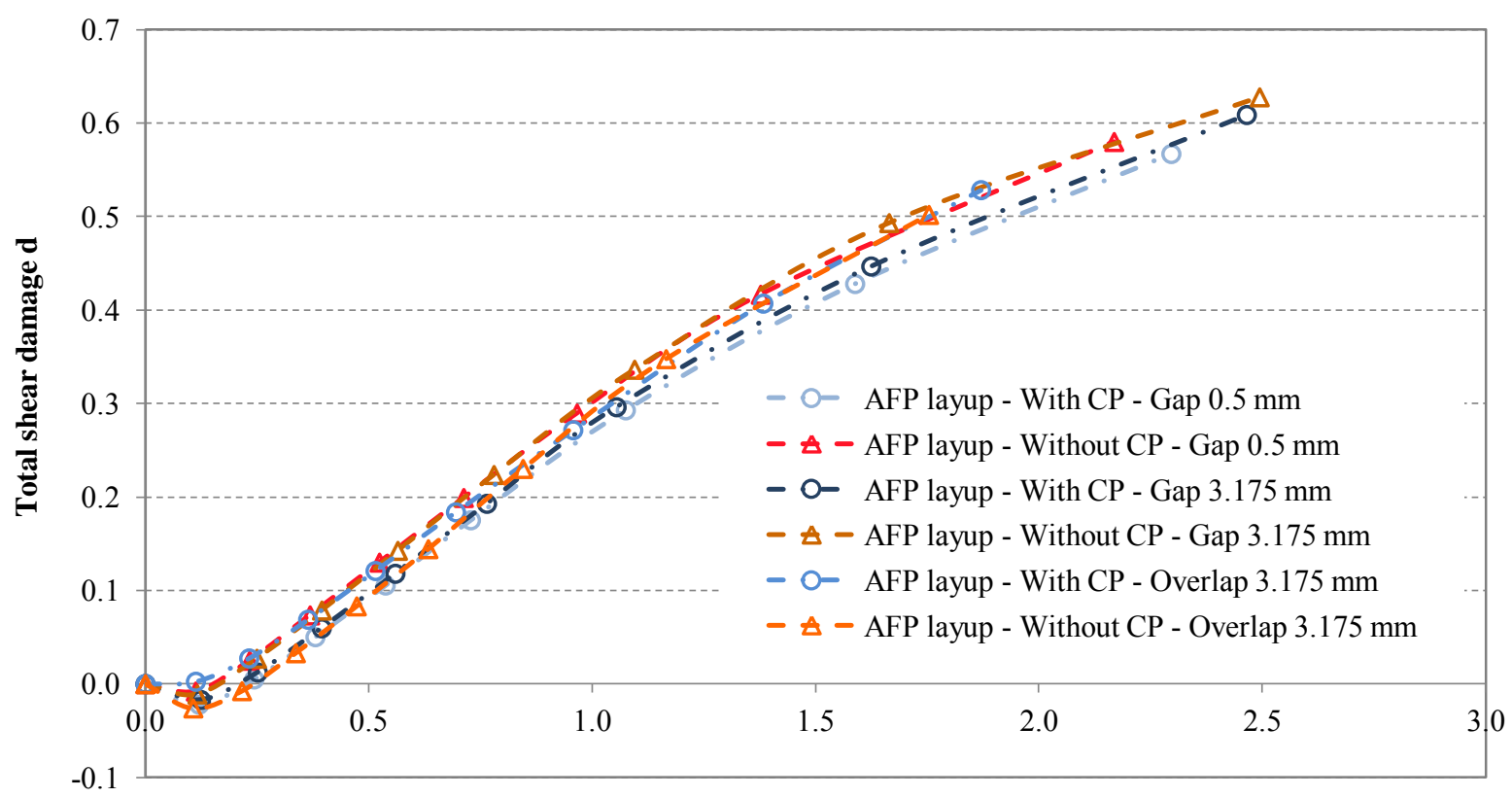

Shear damage force (Yd)1/2 [N]

Figure 10 - Variation of the master damage curve for the laminate as a function of the type of embedded defect with and without caul plate, $\left[\left(-45^{\circ} /+45^{\circ}\right)_{3} /-45^{\circ}\right]$. (For interpretation of the references to color in this figure legend, the reader is referred to the web version of this article.) 


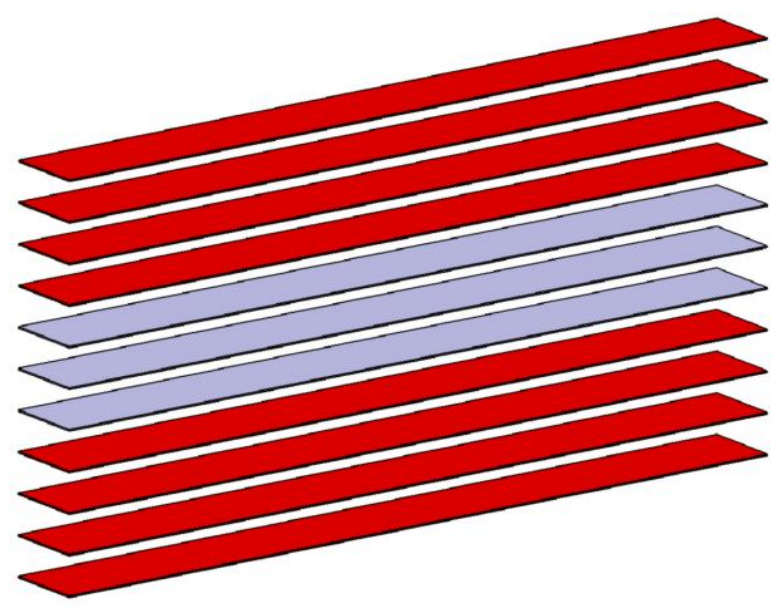

(i) Manual layup - Without defects

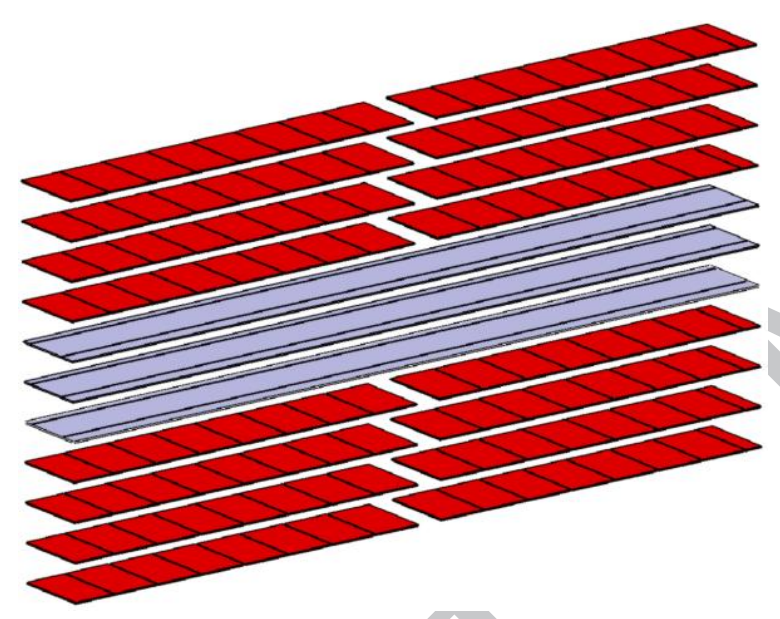

(iii) AFP layup - Gap $3.175 \mathrm{~mm}$

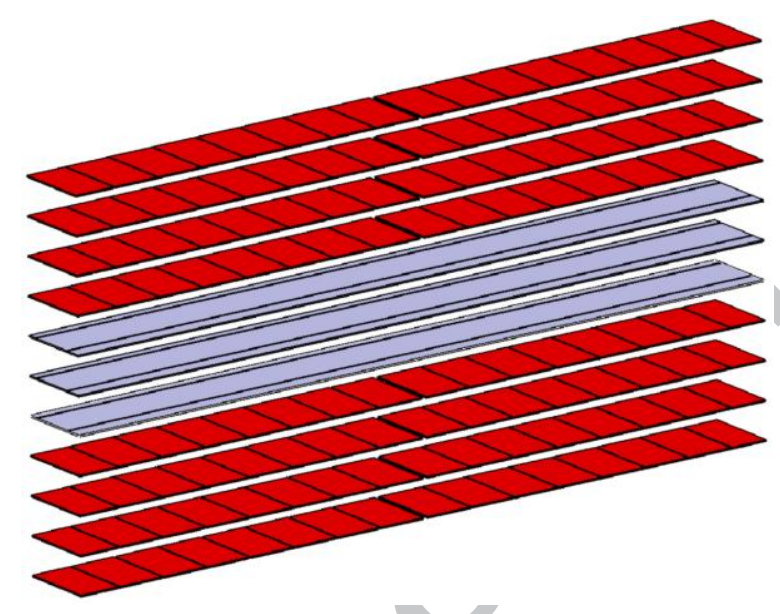

(ii) AFP layup - Gap $0.5 \mathrm{~mm}$

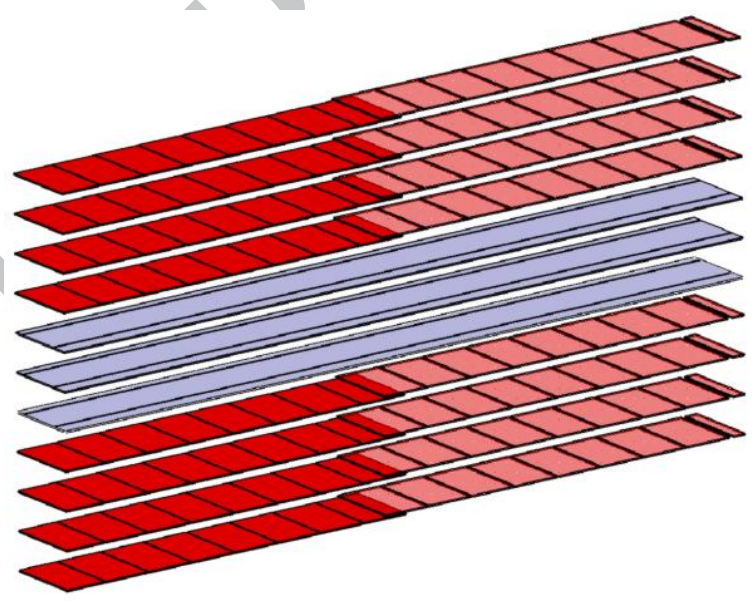

(iv) AFP layup - Overlap $3.175 \mathrm{~mm}$

Figure 11 - Specimen layups, $\left[90^{\circ} / 0^{\circ} 3 / 90^{\circ}\right.$ ] showing embedded defects. Plies oriented at $90^{\circ}$ are shown in red and plies oriented at $0^{\circ}$ are shown in grey. (For interpretation of the references to colour in this figure legend, the reader is referred to the web version of this article). 
(i) Drapage manuel-Avec CP

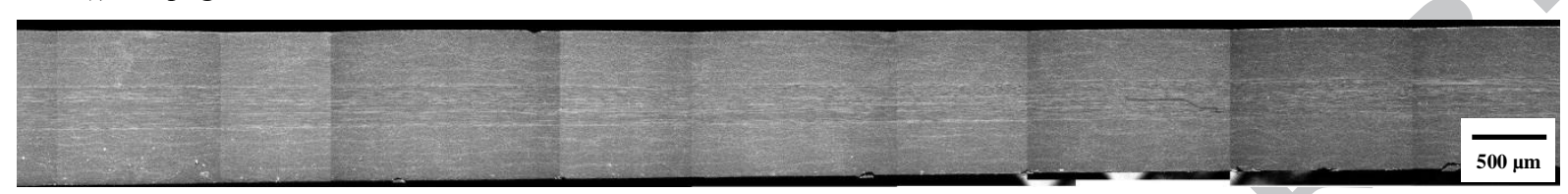

(ii) Drapage AFP - Gap 0,5 mm - Sans CP

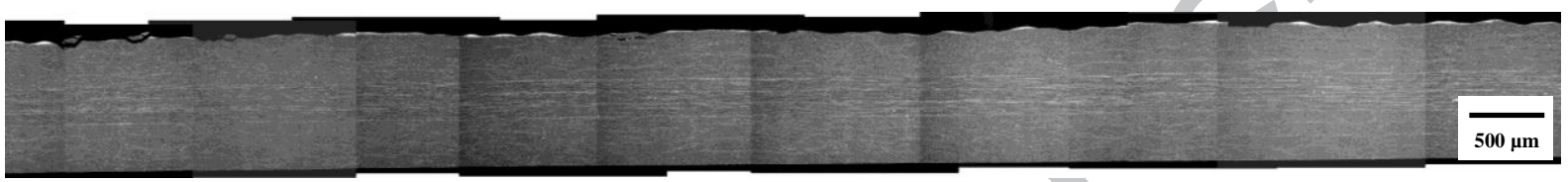

(ii) Drapage AFP - Gap 0,5 mm-Avec CP

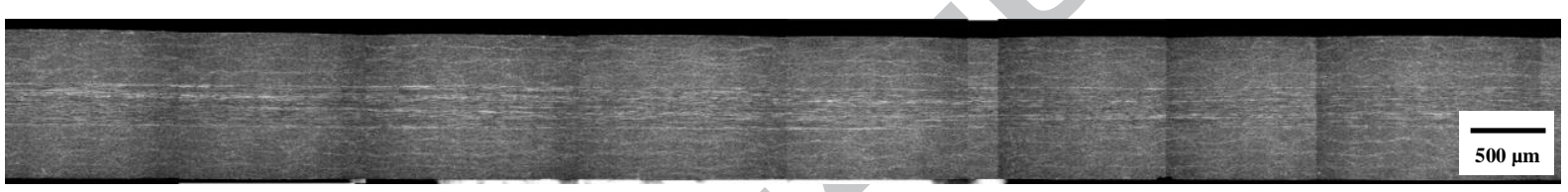

(iii) Drapage AFP - Gap 3,175 mm - Sans CP

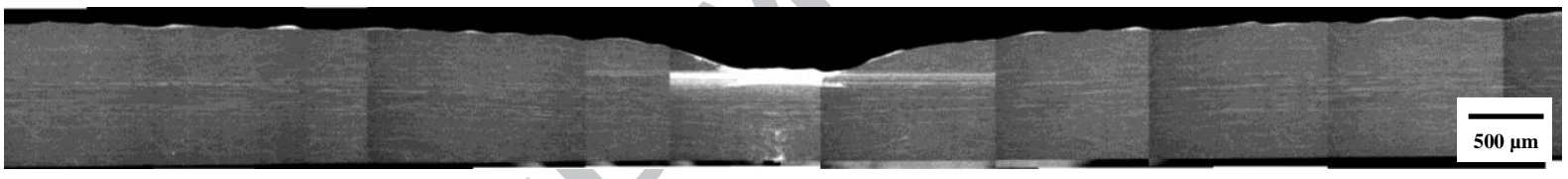

(iii) Drapage AFP - Gap 3,175 mm-Avec CP

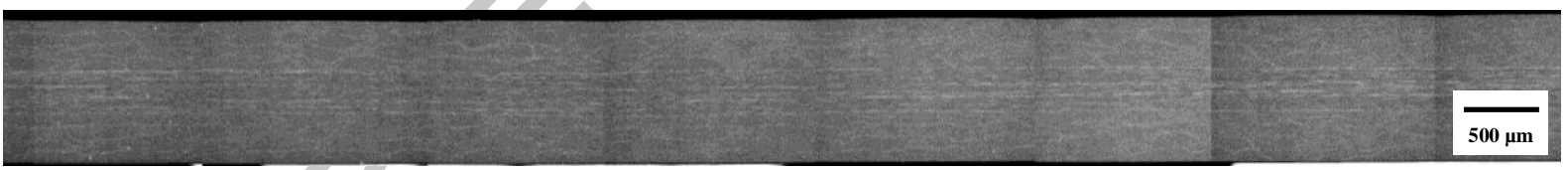

(v) Drapage AFP-Overlap 3,175 mm-Sans CP

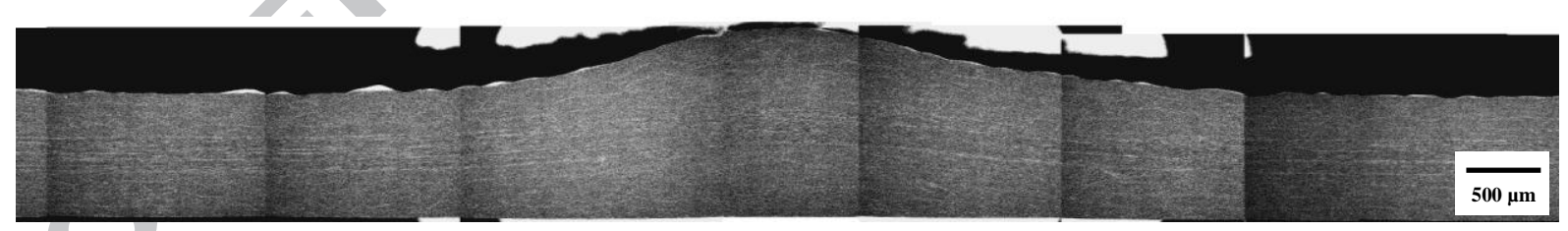

(v) Drapage AFP - Overlap 3,175 mm-Avec CP

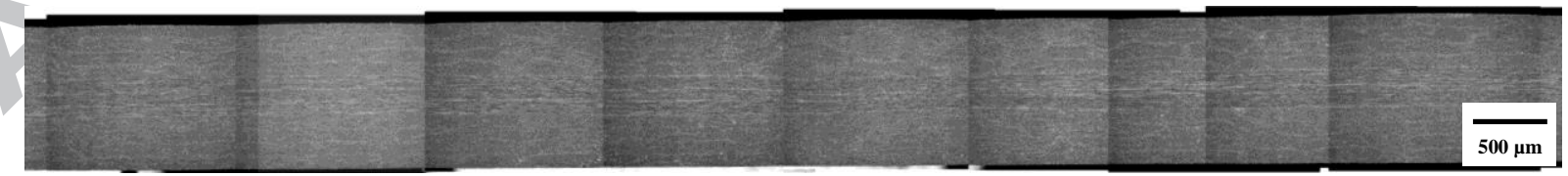

Figure 12 - Microstructural SEM observations in the embedded defect region, $\left[90^{\circ}{ }_{4} / 0^{\circ}{ }_{3} / 90^{\circ}{ }_{4}\right]$ : (i) Manual layup; (ii) Reference AFP layup; (iii) AFP plate with a gap of $3.175 \mathrm{~mm}$; (iv) AFP plate with an overlap of 3.175 


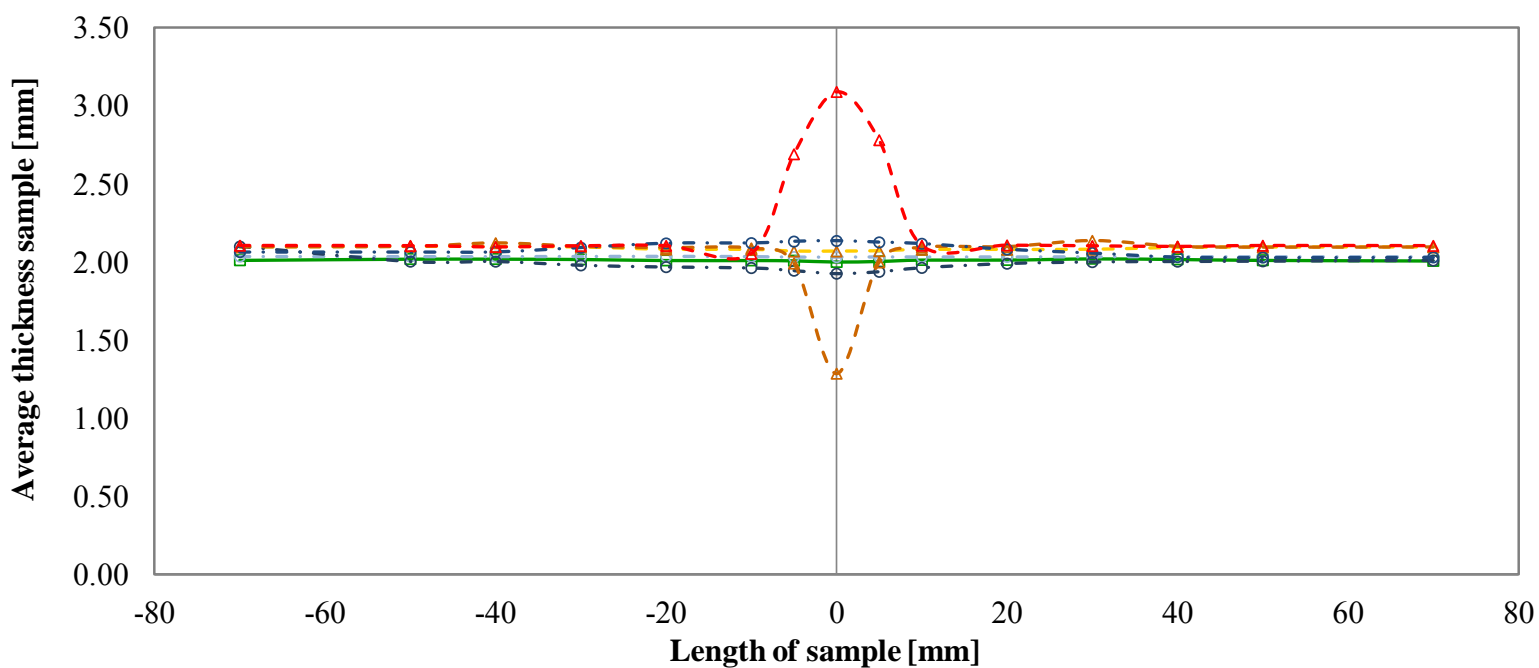

$\square-$ Manual layup - With CP

$--\Delta-$ AFP layup - Without CP - Gap $0.5 \mathrm{~mm}$

- $\bullet \cdot$ - AFP layup - With CP - Gap $0.5 \mathrm{~mm}$

- - AFP layup - With CP - Gap 3.175 mm

- - - AFP layup - Without CP - Gap $3.175 \mathrm{~mm}$

- • $\bullet$ - AFP layup - With CP - Overlap 3.175 mm

- - - AFP layup without CP - Overlap $3.175 \mathrm{~mm}$

Figure 13 - Evolution of the thickness in the length of samples according to the embedded defects introduced during the draping phase, $\left[90^{\circ}{ }_{4} / 0^{\circ} 3 / 90^{\circ}\right]$. (For interpretation of the references to color in this figure legend, the reader is referred to the web version of this article.)

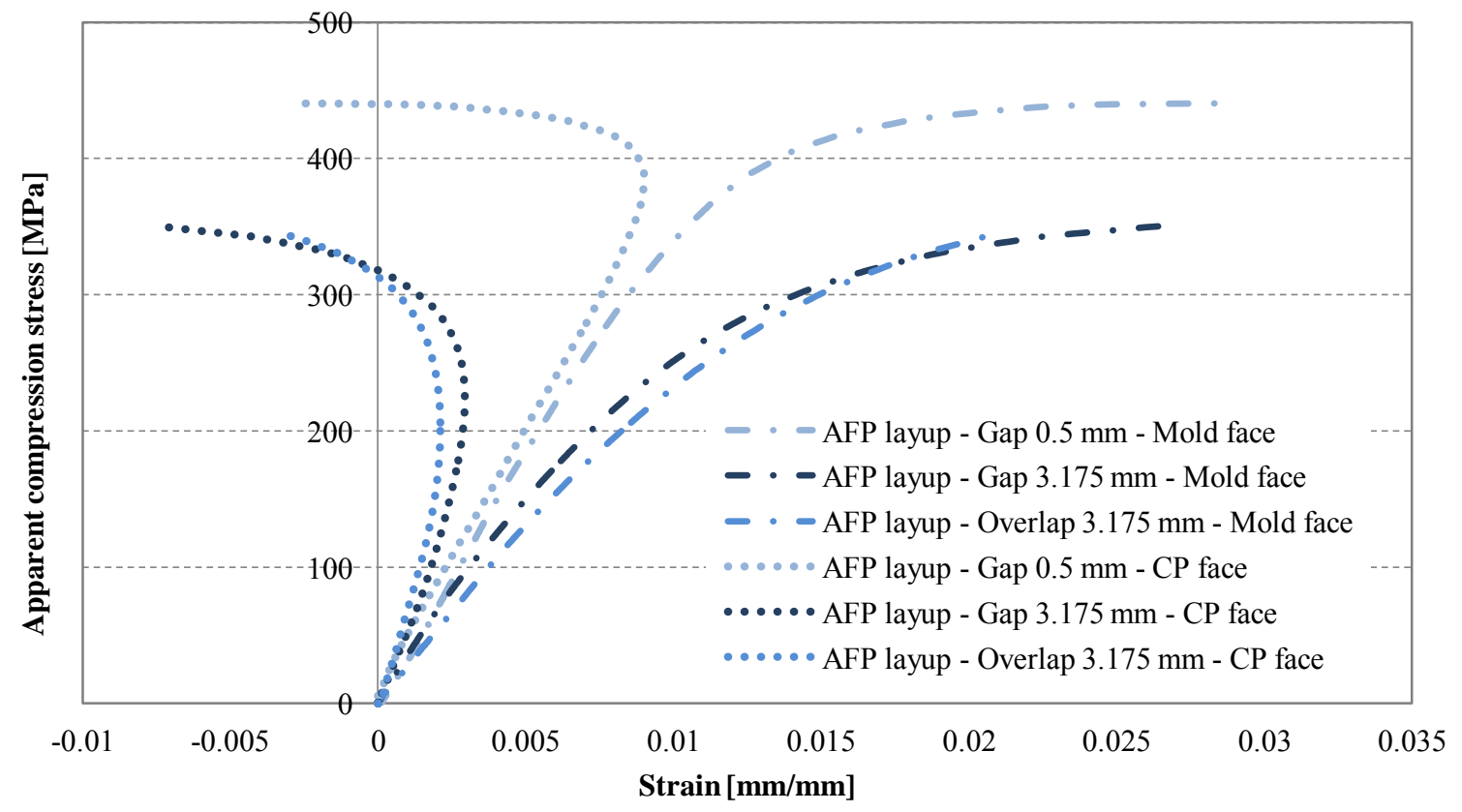


Figure 14 - Comparison of compression stress-strain curves for AFP layup reference and AFP with a gap of $3.175 \mathrm{~mm}$. (For interpretation of the references to color in this figure legend, the reader is referred to the web version of this article.)

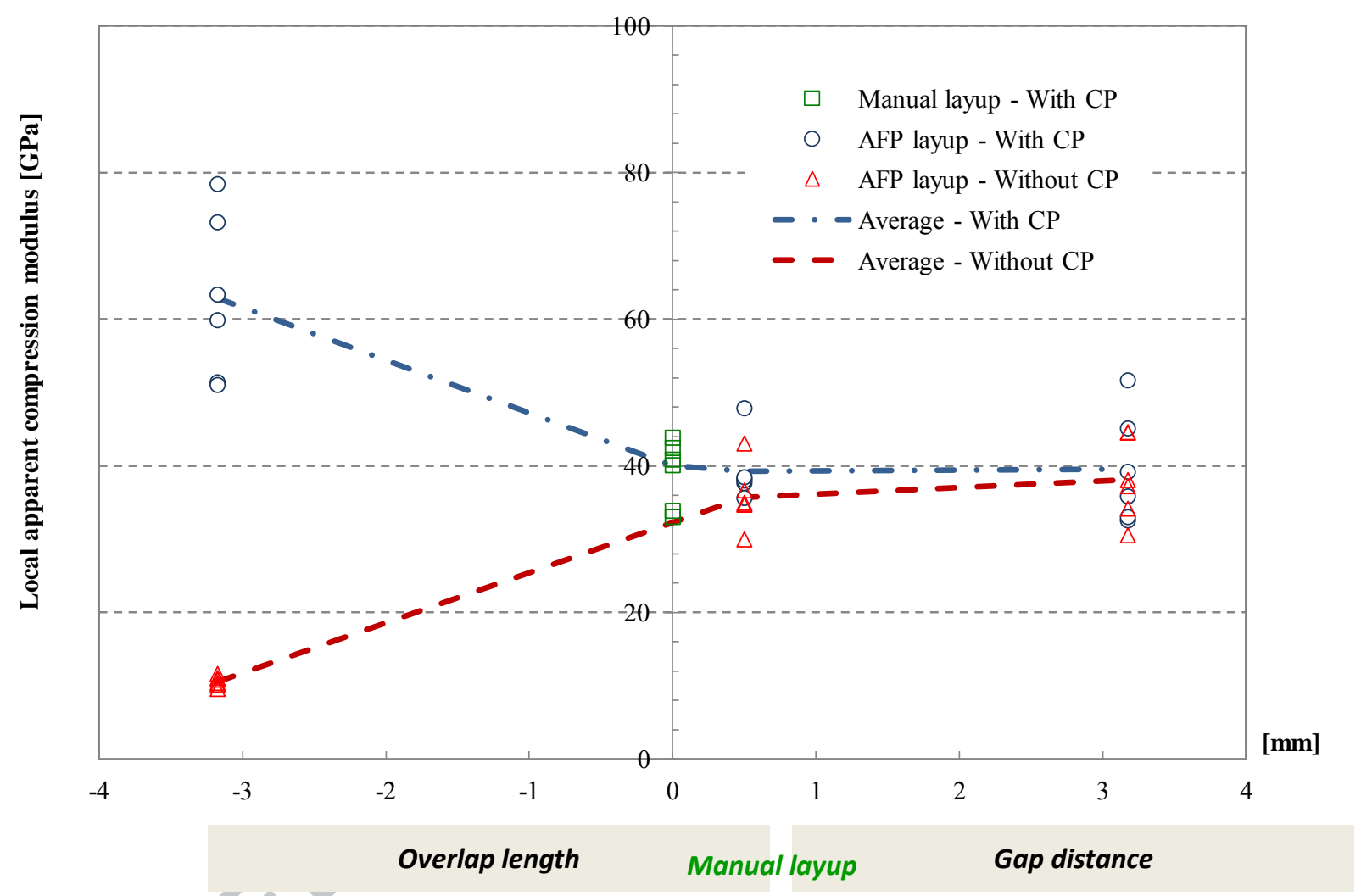

Figure 15-Local apparent compression modulus variation as a function of the type of defect with and without caul plate, $\left[90^{\circ}{ }_{4} / 0^{\circ}{ }_{3} / 90^{\circ}\right.$ ] . (For interpretation of the references to colour in this figure legend, the reader is referred to the web version of this article.) 


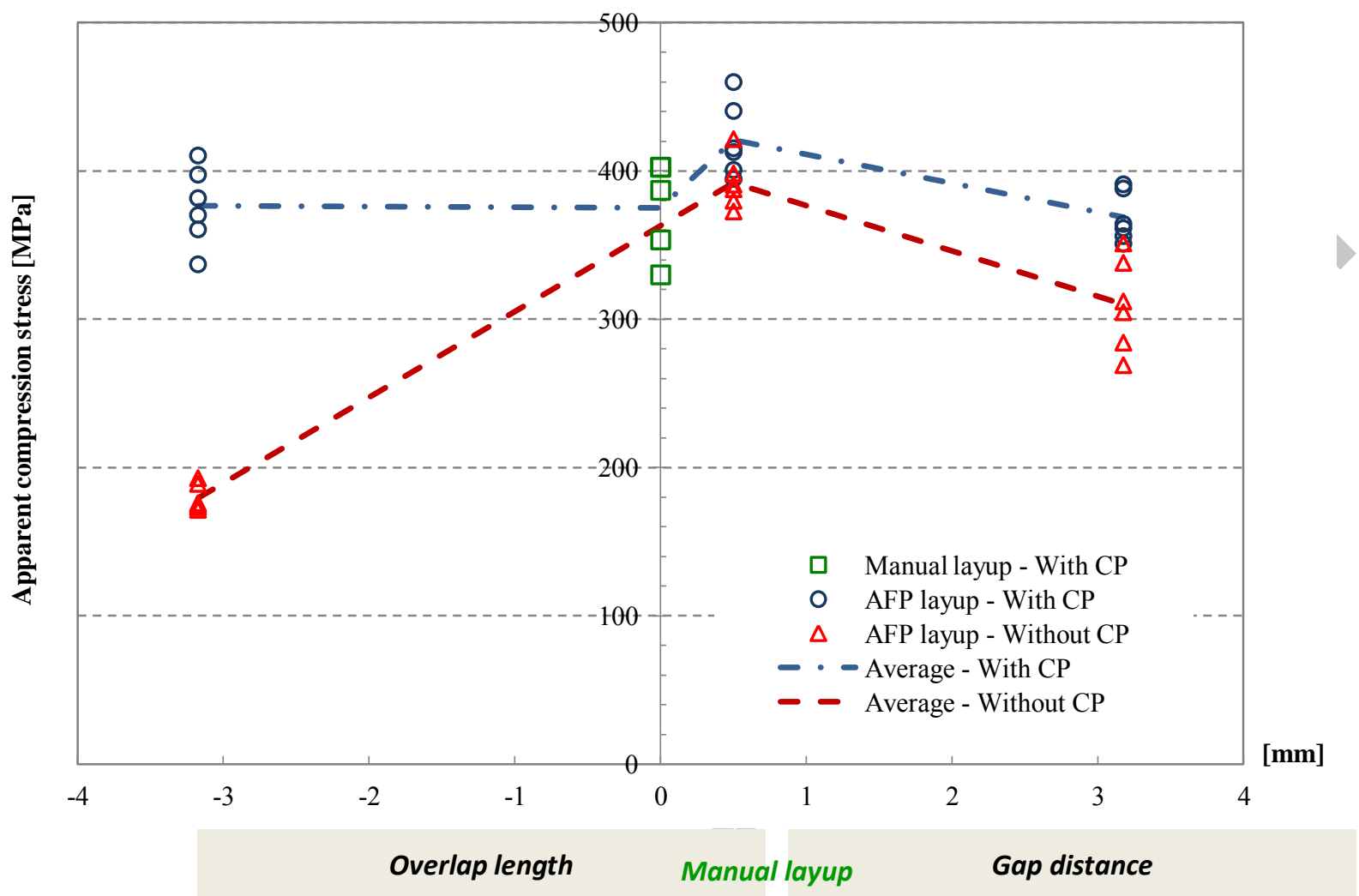

Figure 16 - Apparent compression stress variation at failure in the defect region as a function of the type of embedded defect, with and without caul plate, $\left[90^{\circ}{ }_{4} / 0^{\circ}{ }_{3} / 90^{\circ}{ }_{4}\right]$. (For interpretation of the references to color in this figure legend, the reader is referred to the web version of this article.) 
Table 1. Summary of test results, mean (standard deviation) values

\begin{tabular}{|c|c|c|c|c|}
\hline & \multicolumn{2}{|c|}{ Shear } & \multicolumn{2}{|c|}{ Compression } \\
\hline & $\begin{array}{l}\text { Modulus } \\
\text { GPa }\end{array}$ & $\begin{array}{l}\text { Strength } \\
\mathrm{MPa}\end{array}$ & $\begin{array}{l}\text { Modulus } \\
\text { GPa }\end{array}$ & $\begin{array}{c}\text { Strength } \\
\mathrm{MPa}\end{array}$ \\
\hline $\begin{array}{c}\text { Manual layup - Without embedded } \\
\text { defect - With caul plate }\end{array}$ & $5.19 \pm 0.08$ & $68.2 \pm 1.0$ & $40.01 \pm 4.18$ & $375.2 \pm 32.2$ \\
\hline $\begin{array}{l}\text { AFP layup - Gap } 0.5 \mathrm{~mm} \\
\text { - With caul plate }\end{array}$ & $4.77 \pm 0.12$ & $64.1 \pm 1.7$ & $39.25 \pm 4.31$ & $420.8 \pm 24.9$ \\
\hline $\begin{array}{l}\text { AFP layup - Gap } 3.175 \mathrm{~mm} \\
\text { - With caul plate }\end{array}$ & $4.59 \pm 0.07$ & $59.3 \pm 4.0$ & $39.51 \pm 7.63$ & $368.8 \pm 16.9$ \\
\hline $\begin{array}{c}\text { AFP layup - Overlap } 3.175 \mathrm{~mm} \text { - } \\
\text { With caul plate }\end{array}$ & $4.88 \pm 0.15$ & $67.0 \pm 2.2$ & $62.85 \pm 11.23$ & $376.4 \pm 26.3$ \\
\hline $\begin{array}{l}\text { AFP layup - Gap } 0.5 \mathrm{~mm} \\
\text { - Without caul plate }\end{array}$ & $4.92 \pm 0.10$ & $63.8 \pm 1.3$ & $35.64 \pm 4.24$ & $392.0 \pm 17.0$ \\
\hline $\begin{array}{c}\text { AFP layup - Gap } 3.175 \mathrm{~mm} \text { - } \\
\text { Without caul plate }\end{array}$ & $4.45 \pm 0.11$ & $54.6 \pm 2.1$ & $38.14 \pm 5.60$ & $310.0 \pm 31.2$ \\
\hline $\begin{array}{c}\text { AFP layup - Overlap } 3.175 \mathrm{~mm} \text { - } \\
\text { Without caul plate }\end{array}$ & $4.95 \pm 0.13$ & $63.3 \pm 1.3$ & $10.55 \pm 0.72$ & $179.6 \pm 9.0$ \\
\hline
\end{tabular}

